\title{
Improved engineering method for calculating the strength of the supporting areas of reinforced concrete elements
}

\author{
Olena Krantovska ${ }^{1}$, Mykola Petrov $^{1}$, Liubov Ksonshkevych ${ }^{1}$, Sergii Synii ${ }^{2,}$, and Pavlo \\ Sunak $^{2}$ \\ ${ }^{1}$ Odesa State Academy of Construction and Architecture, 65029 Ditrikhson st. 4, Odesa, Ukraine \\ ${ }^{2}$ Lutsk National Technical University, 43018 Lvivska st. 75, Lutsk, Ukraine
}

\begin{abstract}
According to the results of experimental studies, empirical dependencies were obtained (obtained from the appropriate mathematical models). The advanced (refined) method of engineering calculation of express-estimation of the strength of sloping cross sections of elements of flexible reinforced concrete structures on the basis of comparative analysis of the obtained empirical dependencies and standard accepted methods in the world was developed (nine basic norms are taken: DSTU B.V.2.6-156:2010 (Ukraine), previously operating SNiP 2.03.01-84*, SNB 5.03.01-02 (Belarus), SR 63.13330.2012 (Russia), Eurocode 2, 2004 (European Union), ACI 318-M14 (USA), AIJ Code, 2007 (Japan), CSA 23.3-04 (Canada), DIN 1045-1 (Germany). The coefficient of variation of bearing capacity and accident ratio according to the results of calculations of standard methods are determined. Their comparative analysis is carried out and informative graphic figures are presented.
\end{abstract}

\section{Introduction}

As research and design experience shows, due to the lack of a unified approach that would take into account the calculation of the inclined and normal sections, especially in complex stress-strain state, the problem of ensuring the strength of inclined sections of span reinforced concrete structures remains unsolved.

The construction of a common analysis model that would adequately simulate the stress-strain state and accurately describe the resistance of the structure the effect of the cut in combination with the bending, tensile, compression and torsion, is one of the most difficult tasks in the theory of reinforced concrete. In this regard, in practical calculations of the strength of inclined sections of reinforced concrete elements specialists uses conventional models, the so-called engineering techniques [1-4 etc.].

\footnotetext{
* Corresponding author: sergii.synii@gmail.com
} 


\section{Analysis of publications}

The stress-strain state of complex loaded concrete elements was studied by T.N. Azizov, H.S. Aliev, Y.M. Babych, A.Y.Barashykov, L.V. Baykov, Z.Y. Blikharskii, O.O. Hvozdev, O.S. Horodetskii, B.H. Demchyna, S.A. Dmytriev, L.O. Doroshkevych, V.S. Dorofeev, O.S. Zaliesov, V.M. Karpiuk, P.M. Koval, R.L. Mailyan, A.M. Pavlikov, O.I. Storozhenko, V.V. Tur, Y.O. Shkola, O.F. Yaremenko etc. Among foreign works can be noted the work of R. Walter, A. Vista, L. Cany, M.F. Collins, F. Leongardt, J. Mitchell, K. Modi, J. Morrow, J. Regan, J. Taub, D. Hanson etc.

Study of the influence of longitudinal tensile forces on the strength of inclined sections of reinforced concrete elements described in the works of G. I. Kiriakadi, A. S. Zorich, B.A. Kalaturova, I. V. Volkova and others.

Issues of improvement of the standard calculation methods of durability of reinforced concrete designs are considered in works [5-18].

\section{Purpose of the study}

The purpose of the study is developing an improved (refined) engineering calculation method for express-estimation of the strength of sloping cross-sections of reinforced concrete elements bending on the basis of a comparative analysis of empirical dependencies and world-wide standard methods (nine standards are taken as the basis: Ukraine, previously acting SNiP2.03.01-84*, Belarus, Russia, the European Union, the USA, Japan, Canada, Germany).

\section{Methods, equipment and main characteristics of the research samples}

The set of equipment used in experimental research included standard equipment, provided by the relevant normative methods of conducting this kind of experiments. Also developed special equipment (in accordance with the developed method of planned experimental research). For example, designed and manufactured universal power unit. The principle of operation of these unit is due to the peculiarities of their constructional schemes (Fig. 1-2).

In accordance with the developed technique, everything was tested: 54 two-span continuous beams (fragments of the tests are shown in Fig. 1, b); 6 single-beams to bend; and 18 single-span beams for off-center stretching.

Investigated:

- single-span beams of a rectangular cross-section with dimensions of $100 \times 200 \mathrm{~mm}$ with $h_{0}=175 \mathrm{~mm}$, span $l=9 \cdot h_{0}=575 \mathrm{~mm}$ and shear sections $a / h_{0}=1,2,3$, made of heavy concrete of classes C12/15, C20/25, C30/35, reinforced by two plain frames with the lower rebar $2 \varnothing 12,14,16$ A500S, with the top rebar 2Ø8, 10, 12 A500S and with transverse rebar 2Ø3, 4, 5 Vr-I;

- two-span continuous beams, respectively, $\mathrm{b} \times \mathrm{h}=100 \times 180 \mathrm{~mm}$ with $h_{0}=155 \mathrm{~mm}$, $L=8 \cdot h_{0}, a / h_{0}=1,2,3, \mathrm{C} 12 / 15, \mathrm{C} 20 / 25, \mathrm{C} 30 / 35,2 \varnothing 10,12,14500 \mathrm{~S}, 2 \varnothing 10,12,14$ A500S, 2Ø3, 4, 5 Vr-I.

Single-span beams were tested for non-centrally stretching at $N_{s t} t\left(f_{c k} \cdot b \cdot h_{0}\right)=0.05 ; 0.2$; 0.35 , non-centrally compression $N_{s t} /\left(f_{c k} \cdot b \cdot h_{0}\right)=0.2 ; 0.4 ; 0.6$, in a numerical experiment, modeled using a deformation method based on the results of previous field experiments, on non-centrally compression with $N_{s t} /\left(f_{c k} \cdot b \cdot h_{0}\right)=0.05 ; 0.2 ; 0.35$. The eccentricity of the application of the longitudinal force was changed: $e / h_{0}=-0.25 ; 0 ;+0.25$.

The continuous same beams were tested on the bending by two concentrated forces. 
a)

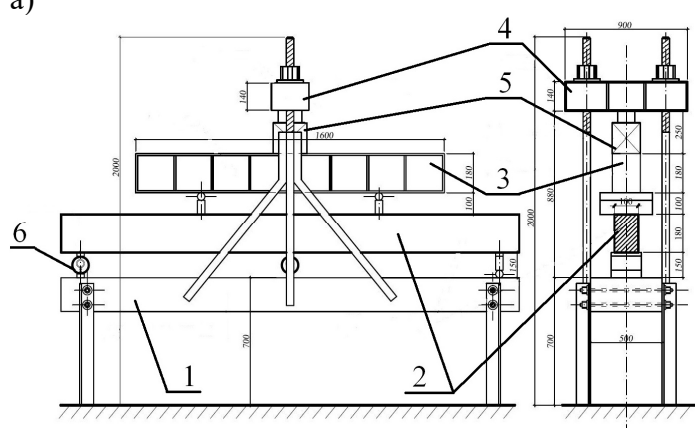

b)

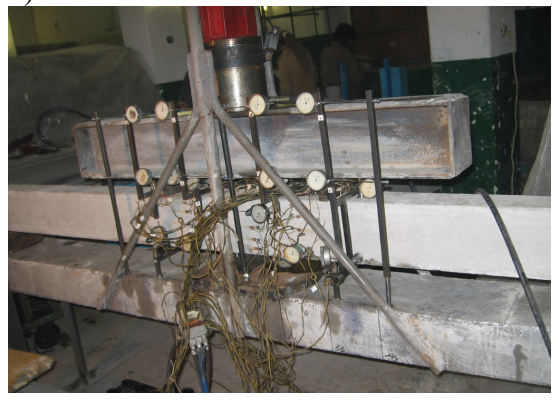

Fig. 1. The power unit developed for testing a continuous beam bending: a) - a constructional scheme; b) - photo fragment of conducting experiments; 1 - mounting bed; 2 - investigated beam specimen; 3 , 4 - traverses; 5 - jack D 50;6 - dynamometer.

a)

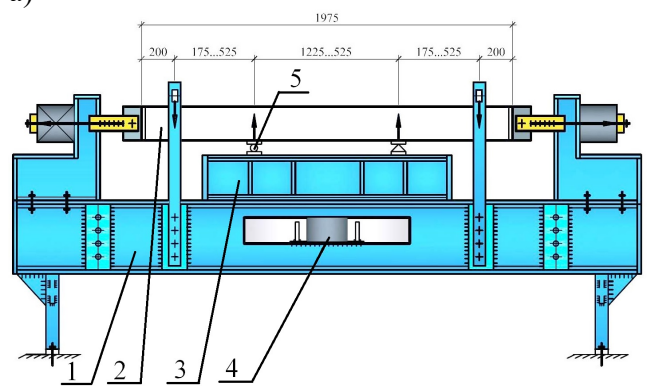

b)

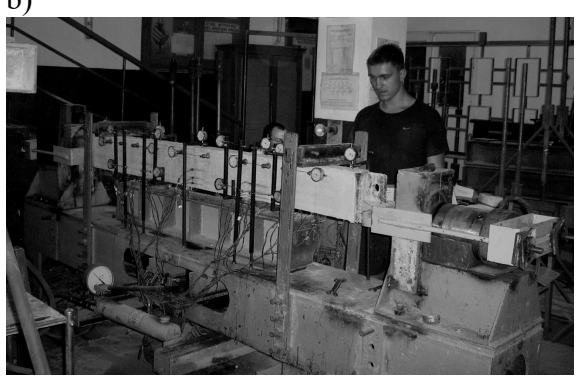

Fig. 2. The power unit for the testing of a single-span beam is developed for a non-center stretch: a) - a constructional scheme; b) - photo fragment of conducting experiments; 1 - mounting bed; 2 - investigated beam specimen; 3 - traverse; 4 - jack D 50; 5 -dynamometer.

The experimental samples were made according to five-factor three-level, close to the properties of the D-optimal, a plan of type Ha 5, [19], and non-centrally stretched samples according to the Box 2 plan.

\section{Research methods}

According to the results of the experiment, new data on the stress-strain state of the supporting areas of non-centrally stretched, compressed and continuous reinforced concrete beams were obtained. The nature of the cracking and the destruction of the experimental elements is illustrated with the fragments of the photo recording experiments shown in Fig. 3, 4.

The express estimation of the strength of sloping cross sections of bending reinforced concrete elements is proposed to be carried out using an advanced engineering method using formulas (1)-(12). For this method, the dependences (7)-(12) are derived, which are based on adequate mathematical models of the main parameters of the workability of experimental beams. These models comprehensively take into account the effect of research factors and have sufficient information security. After removing the nonsignificant ones and recalculating remaining coefficients in the regression equations, replacing the coded variables with the natural values, these models turn into polynomials of the first or second degree. 
a)

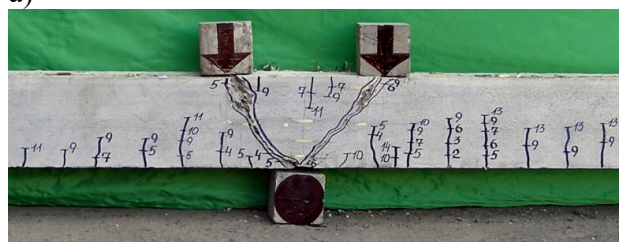

b)

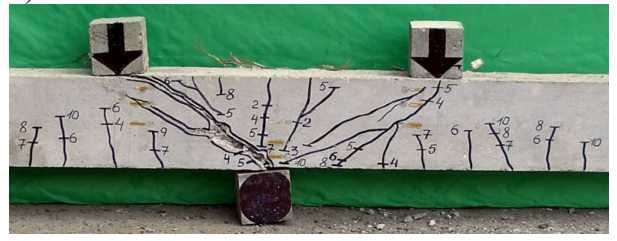

c)

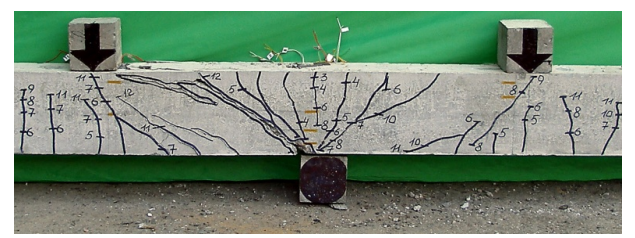

Fig. 3. The nature of cracking and destruction of experimental two-span continuous beams with small (a), middle (b) and large (c) shear span.

Experimental research has shown that part of the non-centrally stretched beams began to collapse due to the fluidity of the upper and lower longitudinal reinforcement (Fig. 4) due to their insufficient number.

a)

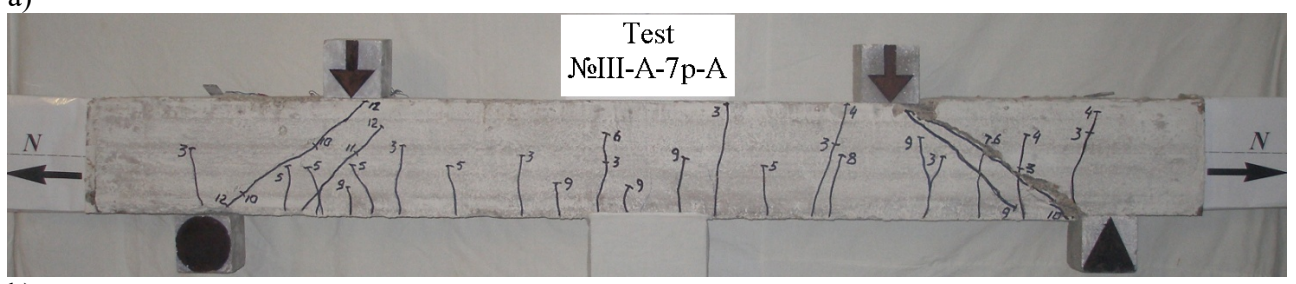

b)

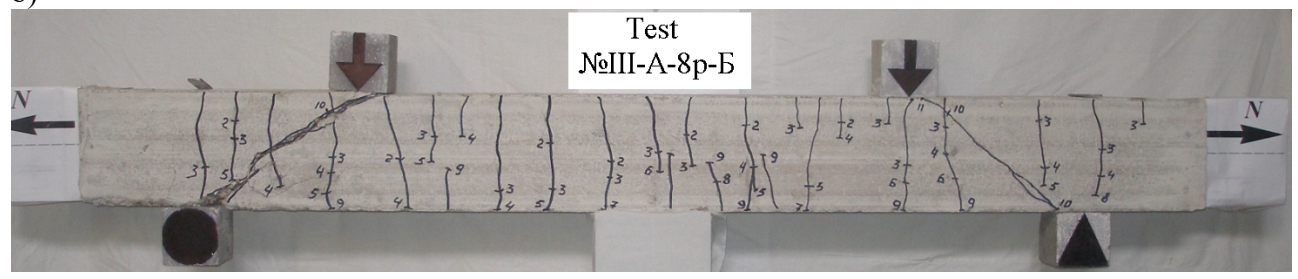

Fig. 4. The disclosure, the formation of new cracks and destruction during the test of a single-span reinforced concrete beam with a non-centrally stretch. The seventh test specimen (a), eighth test specimen (b).

The conditions of strength in this case have the appropriate appearance

$$
\begin{aligned}
& N \leq f_{y d}^{\prime} A_{s}^{\prime}\left(h_{0}-a_{s}^{\prime}\right) / e_{s}, \\
& N \leq f_{y d} A_{s}\left(h_{0}-a_{s}^{\prime}\right) / e_{s}^{\prime},
\end{aligned}
$$

which allow you to pick up the required number of longitudinal reinforcement on a support or limit tensile force $N$.

In the case of a minimum number of longitudinal working reinforcement bars, the collapse of support area, usually a non-centrally extended element, in most cases is caused by the predominant action of the bending moment, which is accompanied by the fluidity of the longitudinal working reinforcements bars at the beginning of the sloping cracks, the minimum height or absence of a compressed concrete zone over a dangerous sloping 
cracks. The condition of the strength of the support area relative to the center of gravity of the upper (mounting) reinforcement bars has the form:

$$
M \leq M_{S}+M_{S W}=M_{S N}+M_{S F}+M_{S W}^{F} .
$$

Additional longitudinal force in the working reinforcement bars, at the beginning of the sloping crack:

$$
N_{S F}=N_{S}-N_{S N}=\left(f_{y d}-\sigma_{S N}\right) A_{S}
$$

where $N_{S N}, \sigma_{S N}$ - respectively, the longitudinal force and normal stresses in the working reinforcement bars due to the longitudinal tensile force.

In general, the condition (3) can be represented:

$$
M \leq V \cdot a+N \cdot e_{\mathrm{s}}^{\prime}-f_{y d} \cdot A_{s} \cdot Z_{s}-q_{\mathrm{sw}} \cdot C_{0}^{2} / 2,
$$

from

$$
V \leq\left[f_{y d} \cdot A_{s}\left(h_{0}-a_{s}^{\prime}\right)+q_{\mathrm{sw}} \cdot C_{0}^{2} / 2-N \cdot e_{\mathrm{s}}^{\prime}\right] / a,
$$

where $q_{\mathrm{sw}}$ - the intensity of the transverse reinforcement, $C_{0}$ is the length of the horizontal projection of the dangerous sloping crack on the longitudinal axis of the beam.

According to the results of experimental studies, the $C_{0}$ index in practical calculations is recommended to be determined from the empirical dependences (7)-(10) obtained from the appropriate mathematical models:

- for ordinary single-span beams:

$$
\begin{aligned}
& \mathrm{C}_{0} / h_{0}=1.114+0.24\left(a / h_{0}-2\right)-0.05\left(\frac{\rho_{W}-0.0030}{0.0014}\right)+0.06\left(\frac{\rho_{f}-0.0180}{0.0050}\right)- \\
& -0.05\left(a / h_{0}-2\right)\left(\frac{\rho_{W}-0.0030}{0.0014}\right)+0.06\left(a / h_{0}-2\right)\left(\frac{\rho_{f}-0.0180}{0.0050}\right)-0.02\left(\frac{C-25}{10}\right)\left(\frac{\rho_{f}-0.0180}{0.0050}\right),
\end{aligned}
$$

where $a / h_{0}$ - the relative span of shear; $\rho_{W}$ i $\rho_{f}$ - coefficients of transverse and longitudinal beam reinforcement; $C$ - class of concrete in $\mathrm{MPa}$;

- for non-centrally stretched beams:

$$
\mathrm{C}_{0} / h_{0}=1.246-0.007\left(\frac{N_{p} / f_{c k} b h_{0}-0.200}{0.148}\right)+0.002\left(e / h_{0}\right) / 0.25,
$$

where $N_{p} /\left(f_{c k} \cdot b \cdot h_{0}\right)$ - level of the stretching longitudinal force $N_{p}$, dimensions of the cross section $b h_{0}$, and characteristic resistance of the concrete to the compression is $f_{c k} ; e / h_{0}$ relative eccentricity of applying longitudinal force;

- for non-centrally compressed beams:

$$
C_{0} / h_{0}=1.43+0.25\left(a / h_{0}-2\right)+0.063\left(\frac{\rho_{f}-0.0180}{0.0050}\right)+0.063\left(a / h_{0}-2\right)\left(\frac{\rho_{f}-0.0180}{0.0050}\right) ;
$$

- for continuous two-span beams: 


$$
\begin{aligned}
& \mathrm{C}_{0} / h_{0}=1.37+0.56\left(a / h_{0}-2\right)-0.06\left(\frac{C-25}{10}\right)-0.07\left(\frac{\rho_{W}-0.0034}{0.0016}\right)-0.21\left(\frac{\rho_{f u}-0.0150}{0.0049}\right)+ \\
& +0.17\left(\frac{\rho_{f s}-0.0150}{0.0049}\right)-0.05\left(\frac{\rho_{f s}-0.0150}{0.0049}\right)^{2}-0.05\left(a / h_{0}-2\right)\left(\frac{C-25}{10}\right)-0.07\left(a / h_{0}-2\right) \times \\
& \times\left(\frac{\rho_{W}-0.0034}{0.0016}\right)-0.15\left(a / h_{0}-2\right) \times\left(\frac{\rho_{f u}-0.0150}{0.0049}\right)+0.12\left(a / h_{0}-2\right) \times\left(\frac{\rho_{f b}-0.0150}{0.0049}\right)- \\
& -0.05\left(\frac{\rho_{W}-0.0034}{0.0016}\right) \times\left(\frac{\rho_{f u}-0.0150}{0.0049}\right)+0.05\left(\frac{\rho_{W}-0.0034}{0.0016}\right)\left(\frac{\rho_{f s}-0.0150}{0.0049}\right)- \\
& -0.03\left(\frac{\rho_{f u}-0.0150}{0.0049}\right) \cdot\left(\frac{\rho_{f s}-0.0150}{0.0049}\right),
\end{aligned}
$$

where $\rho_{f t}$ i $\rho_{f s}$ - the reinforcement coefficients, respectively, of the lower and upper zone of beam.

Also, there was a destruction of experimental reinforced concrete beams behind the sloping strip between the concentrated force and the support. According to the results of experiment, for such a case the destruction, the condition of the strength of the short strip in practical calculations is recommended to be determined by the empirical inequality:

$$
V \leq \varphi_{c_{1}}^{*} f_{c d} b h_{0}
$$

where $\varphi_{c_{1}}^{*}$ - a coefficient which integrally takes into account the influence of the concrete class, transverse reinforcement and the previous stresses on the working reinforcements. For ordinary and non-centrally compressed reinforced concrete beams with a small shear span experimentally $\left(\varphi_{c_{1}}^{*}=V / f_{c d} b h_{0}\right)$ an adequate mathematical model of this coefficient has been obtained, which, after corresponding transformations, has become a form

$$
\varphi_{c_{1}}^{*}=0.3-0.09(C-25) / 10+0.01\left(\rho_{w}-0.0035\right) / 0.00145 \text {, }
$$

where $\rho_{w}$ - the coefficient of transverse reinforcement.

The following are the results of a comparative analysis of empirical dependencies and world-wide normative methodologies (the nine standards are taken as the basis: Ukraine, previously acting SNiP 2.03.01-84*, Belarus, Russia, the European Union, the USA, Japan, Canada, Germany).

For reliability and safety of the forecasting of the bearing capacity of the supporting areas of the span reinforced concrete elements, their bearing capacity according to the standards is determined taking into account their complex stress-strain state.

In the current Ukrainian [1], harmonized Belarusian [2], international European [3] and American [4] normative documents, the calculation of elements for the action of the transverse force is based on the "truss model", which consists of stretched and compressed rod elements. However, the use of the truss analogy in the normative documents of different countries has its own peculiarities [5]. For example, as noted in [6], despite the similarity of the methods used, the provisions of DBN and the corresponding Eurocode 2 
differ significantlu, which should be taken into account when comparing the results of calculations on these norms among themselves.

The study of the strength of sloping sections is considered in [11-16]. Among the important criteria chosen for the comparative analysis was the coefficient of variation in strength (Fig. 5).

Among the important criteria chosen for the comparative analysis, the coefficient of variation in strength was selected (Fig. 5):

$$
v=\frac{\sigma}{b_{0}} \cdot 100 \%
$$

where $\sigma=\sqrt{\sum \frac{\left(\hat{V}_{\text {exp }}-V\right)^{2}}{n-1}} ; \sum\left(\hat{V}_{\exp }-V\right)^{2}$ is average square deviation; $b_{0}$ is arithmetic average experimental value of bearing capacity $\hat{V}_{\exp } ; n$ is number of test specimens; and the accident ratio (Fig. 6):

$$
k_{a}=\frac{n_{a}}{n}
$$

where $n_{a}$ - number of test specimens, bearing capacity of the supporting areas of which more than $10 \%$ exceeds the actual values.

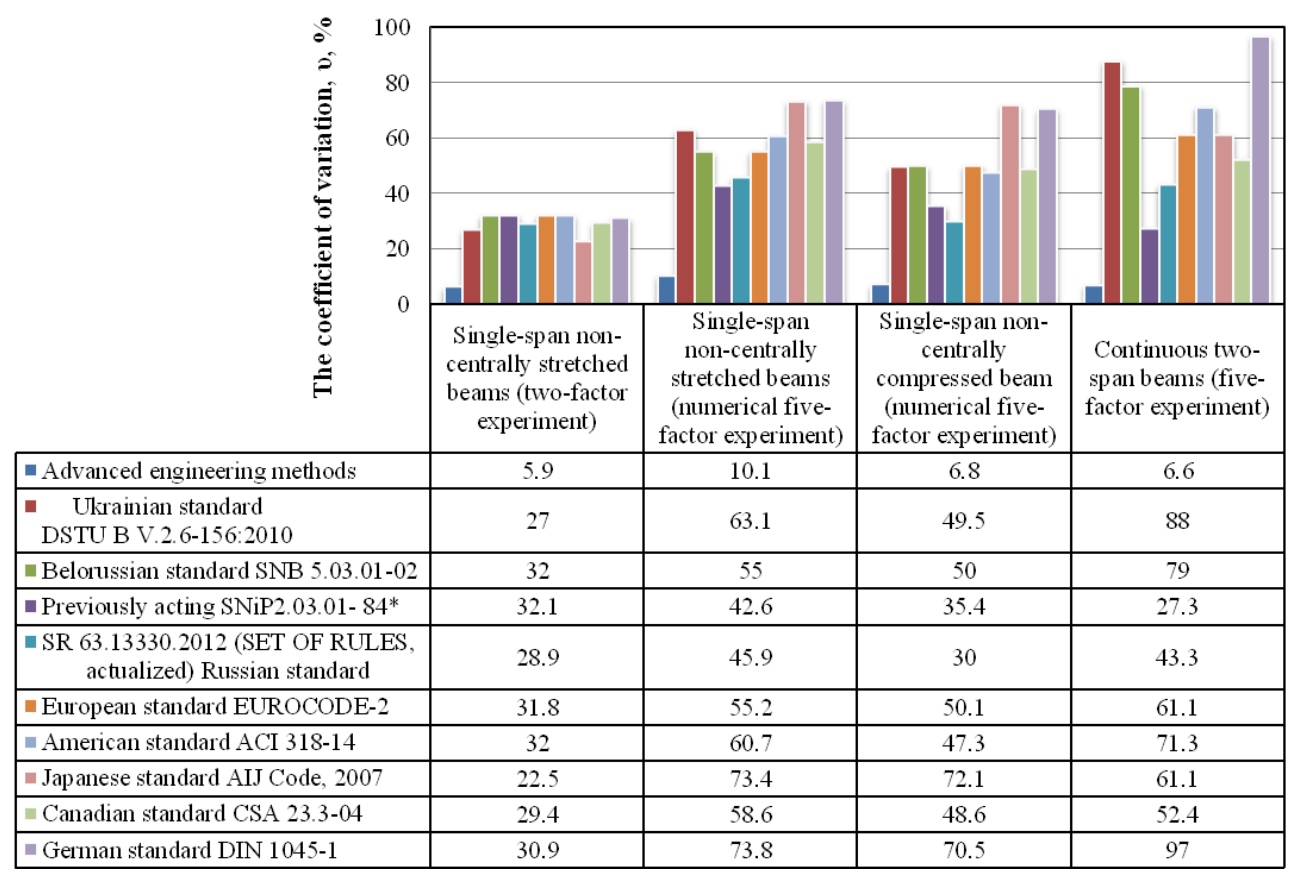

Fig. 5. Comparison of the results of calculations of the coefficient of variation.

Calculated formulas for the SNiP 2.03.01-84* previously operating in Ukraine and the new Russians formulas have the best convergence of calculation and research data of bearing capacity in the supporting areas of non-centrally compressed beams; according to other norms, the discrepancy is within the range of 53 to $73.8 \%$. Accident ratio $k_{a}=0$, that is the most reliable. Similar results are obtained for non-centrally compressed beams. For 
continuous beams, the bearing capacity can be relatively satisfactorily determined according to the old standards $(v=27.3 \%)$, while other norms show a higher coefficient $(v=43$ to $97 \%)$, with a rather low accident ratio.

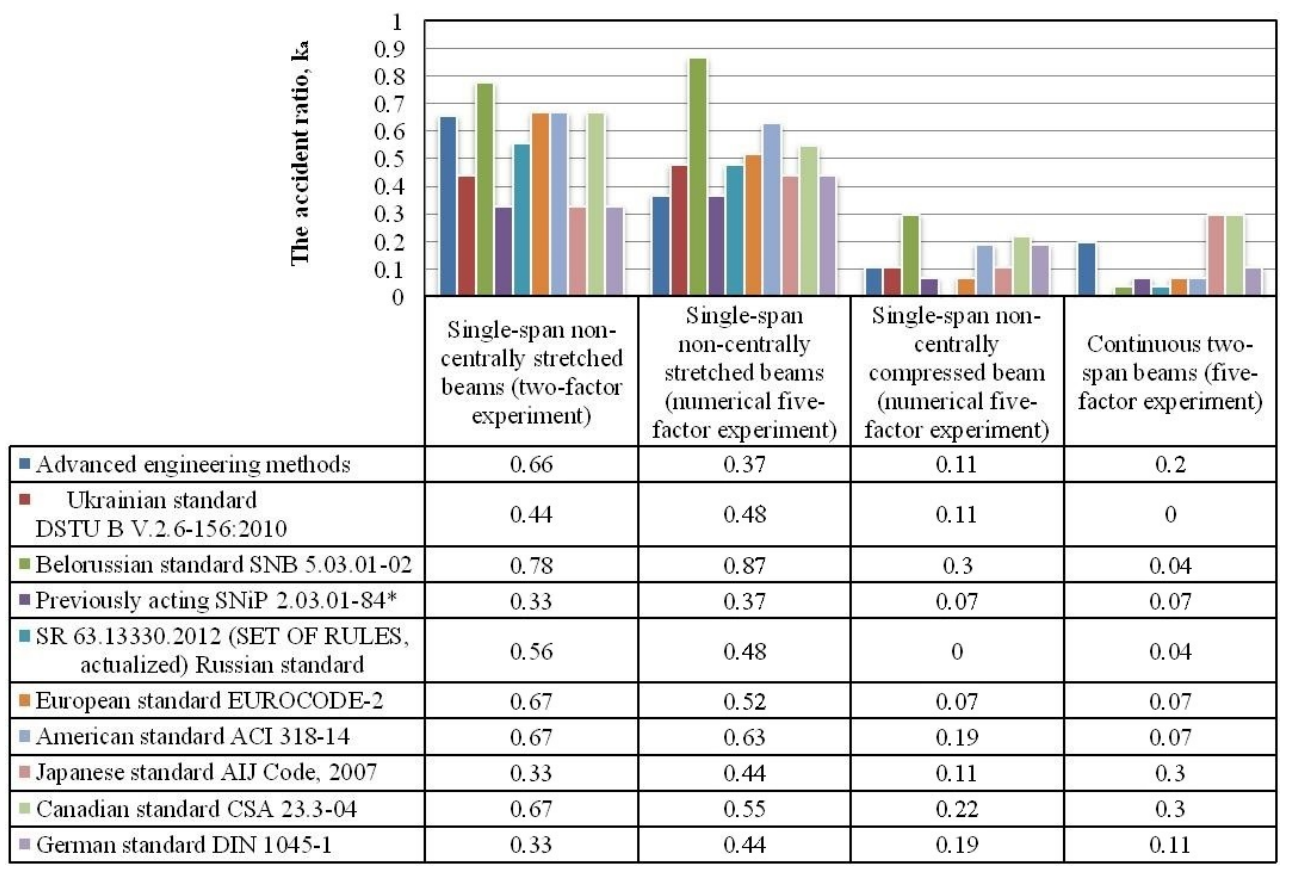

Fig. 6. Comparison of the results of calculations of the accident ratio.

Comparison of the experimental and calculated strength values of the supporting areas of non-centrally stretched and compressed beams, as well as continuous, determined by the recommendations and requirements of various standards, showed, on the one hand, their satisfactory convergence (coefficient of variation $v=20$ to $74 \%$ ), and on the other hand, insufficient reliability of the calculated formulas of these norms, especially for samples with large shear spans.

\section{Conclusions}

An improved engineering methodology for calculating the strength of the supporting areas of the investigated reinforced concrete elements proposes, on the basis of the obtained empirical dependencies, a consistent consideration of all possible destructive schemes and adequately reflects the influence of the research factors on the bearing capacity of the beams. The comparison of the calculated values of the coefficient of variation of bearing capacity of the supporting areas of the experimental reinforcement concrete elements showed satisfactory convergence $(v<12 \%)$.

\section{References}

1. National standard of Ukraine, DSTU B V.2.6-156:2010, Structures of buildings and erection. Concrete and reinforced concrete structures made of heavy concrete. Design rules, Minregionbud Ukrainy, Kyiv, (2010). 
2. National standard of Belarus, SNB 5.03.01-02. Plain and reinforced concrete structures, Minstroyarhitektury, Minsk, (2002).

3. European standard, EN 1992-1-1 (2004). Eurocode 2: Design of Concrete structures Part 1-1: General rules and rules for buildings, CEN, Brussels, (2004).

4. National standard of the USA, Building Code Requirements for Structural Concrete (ACI 318M-14) and Commentary (ACI 318RM-14), ACI, Mich., (2014).

5. V.M. Karpiuk, O.M. Krantovska, O.M. Kotsiurubenko, Gazette OSACEA, 57, 182-188, (2015).

6. V.M. Babaiev, A.M. Bambura, O.M. Pustovoytova and others under general supervision by V.S. Shmukler, Practical calculation of elements of reinforced concrete structures on DBN.2.6-98:2009 in comparison with calculations according to SNiP 2.03.01-84* and EN 1992-1-1 (Eurocode 2), Golden pages, Kharkiv, (2015).

7. V.M. Karpiuk, Calculated force resistance models of span concrete structures in case of bending stress state (monograph), OSACEA, Odesa, (2014).

8. V.S. Dorofeev, V.M. Karpiuk, E.N. Krantovska, Strength, crack resistance and deformability of continuous reinforced concrete beams (monograph), Even, Odesa, (2010).

9. V.S. Dorofeev, V.M. Karpiuk, N.N. Petrov, Strength, deformability and crack resistance of the support of inclined sections of eccentrically stretched, compressed of reinforced concrete beams (monograph), Even, Odesa, (2011).

10. O.M. Kotsiurubenko, O.M. Krantovska, V.M. Karpiuk. Building constructions, SE NDIBK (NIISK), Kyiv, 82, 166-175, (2015).

11. V.P. Mitrofanov. Stress-strain state, strength and cracking of reinforced concrete elements in transverse bending. - Auth. abstr. of Diss. PhD, speciality 05.23.01 "Building structures, buildings and structures", M., (1981).

12. O. Andriichuk, V. Babich, I. Yasyuk, S. Uzhehov, MATEC Web of Conferences, 116, 02001, 1-9, (2017).

13. O.V. Andriichuk, E.M. Babych, Materials Science, New York, 52, 4, 509-513 (2017).

14. Ahmed B. Shurain, J. of King Saud Univ. - Engineering Sciences, 25, 65-74 (2013).

15. O. Mikulich, V. Shvabyuk, I. Pasternak, O. Andriichuk, Mechanics Research Communications, 91, 107-111, (2018).

16. V.V. Tur, A.A. Kondratchik. Calculation of reinforced concrete structures under the action of cutting forces: monograph, Publ. BGTU, Brest, (2000).

17. Umer Farooq and K.S. Bedi, Conf. Structural Engineering Convention 2014 (SEC2014), Delhi, 3477-3488, (2014).

18. F.J. Vecchio and M.P. Collins, ACI J., 83, 2, 219-231, (1986).

19. V.A. Voznesensky, Static methods of experiment planning in technical and economic research, Finance and Statistics, (1981). 